\title{
A Case of Chaunocephalosis by Chaunocephalus ferox (Digenea: Echinostomatidae) in an Oriental White Stork, Ciconia boyciana, in Korea
}

\author{
Seongjun Choe', Dongmin Lee', Hansol Park', Hyeong-Kyu Jeon'1, Youngsun Lee², Ki-Jeong Na ${ }^{2,3}$, \\ Shi-Ryong Park ${ }^{4}$, Keeseon S. Eom, ${ }^{1, *}$ \\ ${ }^{1}$ Department of Parasitology, Medical Research Institute and Parasite Resource Bank, School of Medicine, Chungbuk National University, Cheongju \\ 28644, Korea; ${ }^{2}$ The Wildlife Center of Chungbuk, Cheongju 28116, Korea; ${ }^{3}$ College of Veterinary Medicine, Chungbuk National University, Cheongju \\ 28644, Korea; ${ }^{4}$ Korea Institute of Oriental White Stork Rehabilitation Research, Korea National University of Education, Cheongju 28173, Korea
}

\begin{abstract}
We intended to describe a case of chaunocephalosis and morphological characteristics of its causative agent, Chaunocephalus ferox, recovered from an oriental white stork, Ciconia boyciana, in the Republic of Korea. An oriental white stork was referred to the Wildlife Center of Chungbuk in Korea in February 2014 for severe depression with cachexia and it died the next day. At necropsy, the stomach was severely expanded and 7 thick-walled nodules were observed in the upper part of the intestine. Although the stomach was filled with full of foreign materials, the intestine was almost empty. The nodules were globular and total 9 flukes were recovered. They were 8,030-8,091 $\mu$ m in length and 3,318$3,333 \mu \mathrm{m}$ in maximum width. Because the flukes had bulbous forebody with short narrow subcylindrical hindbody, 27 collar spines, and vitelline follicles not reaching to the posterior end, the specimens were identified as being $C$. ferox. The cyst formation induced thickening of the intestinal wall with narrowing of the lumen that could have contributed to the gastric impaction to the death of the host. This is the first described case of chaunocephalosis and its causative agent $C$. ferox found from an oriental white stork in Korea.
\end{abstract}

Key words: Chaunocephalus ferox, Ciconia boyciana, chaunocephalosis, gastric impaction

\section{INTRODUCTION}

The oriental white stork, Ciconia boyciana, is a large bird found in Eastern Asia, including China, Japan, Korea, Mongolia, Russia, and Taiwan. Although this avian species has been originally inhabited in the Korean Peninsula, its population has been rapidly declined. It is believed that all breeding populations in Korea became extinct in the 1970s. At present, there are only small wintering populations that are found irregularly at various locations in Korea, including Cheonsu-man ('man' means 'bay'), Haenam-gun (county), Suncheon-man, the estuary of Nakdong-gang ('gang' means 'river'), and Jeju-do (province) $[1,2]$. Because of its small global population, the oriental white stork is listed as an endangered species on the Red List of

- Received 16 December 2015, revised 3 June 2016, accepted 20 July 2016.

*Corresponding author (kseom@chungbuk.ac.kr)

(C) 2016, Korean Society for Parasitology and Tropical Medicine

This is an Open Access article distributed under the terms of the Creative Commons Attribution Non-Commercial License (http://creativecommons.org/licenses/by-nc/4.0) which permits unrestricted non-commercial use, distribution, and reproduction in any

medium, provided the original work is properly cited.
Threatened Species of the International Union for Conservation of Nature (IUCN). Its population is estimated to consist of 1,000 to 2,499 mature individuals in the world. These numbers are decreasing. In Korea, the stork is protected by the government, and the Korea Institute of Oriental White Stork Rehabilitation Research (KIOWSRR) was established in 1996 to restore the breeding populations in Korea [2,3].

Chaunocephalosis is an infection of echinostomatid flukes that belong to the genus Chaunocephalus. These flukes induce granulomatous nodules on the intestinal wall in which they then live. The ciconiform birds, including the African openbilled stork (Anastomu lamelligerus), Asian open-billed stork (Anastomus oscitans), oriental white stork (C. boyciana), white stork (Ciconia ciconia), maguari stork (Ciconia maguari), black stork (Ciconia nigra), and black-necked stork (Xenrhynchus asiaticus) are known to be the main definitive hosts for these echinostomes [4-6].

Chaunocephalus ferox is the type species of the genus. The first pathological report of this fluke infection was recorded by Patnaik et al. in 1969 [7]. Since then, several reports on the path- 
ological findings of this fluke infection in different hosts and localities have been published [8-12]. Despite the differences in hosts and locations, all reported cases have similar histopathological features, including traumatic destruction of tissues with hemorrhages, inflammatory cell infiltrations, and thickening of the intestinal wall due to fibrosis [7-12]. The infected birds exhibit diarrhea, listlessness, and loss of appetite before dying [7-12]. This fluke infection has been reported in both captive and wild stork populations and constitutes a serious health concern in terms of the management of these birds. However, chaunocephalosis and its causative agent were not reported before in Korea.

Therefore, we intended to describe a case of chaunocephalosis and morphological characteristics of its causative agent, $C$. ferox, recovered from an oriental white stork, C. boyciana, in the Republic of Korea.

\section{CASE RECORD}

An 11-year-old oriental white stork was referred to the Wildlife Center of Chungbuk (WCC) from KIOWSRR for the treatment in February 2014. The bird was an adult female with a
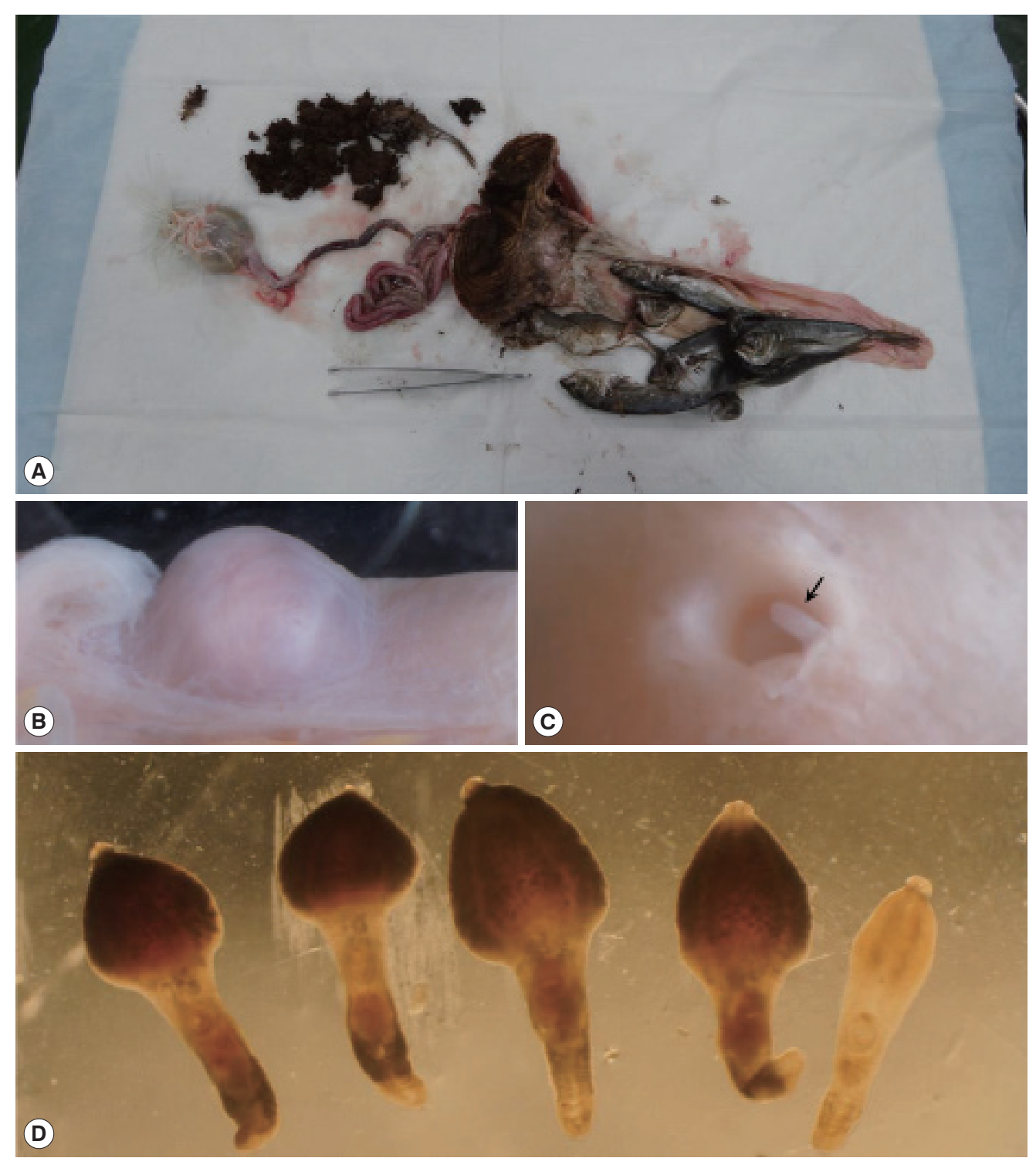

Fig. 1. Chaunocephalus ferox in an oriental white stork (Ciconia boyciana). (A) The stomach filled with dark-brown colored foreign materials and intact sardines. (B) A cyst on the intestinal wall. (C) The cyst opened into the lumen of the intestine via a perforation in the mucosal lining. (D) C. ferox recovered from the cyst. Four mature specimens with a young adult worm. 
weight of $3.05 \mathrm{~kg}$ and showed severe depression accompanied by cachexia. However, the bird died the next day. To determine the cause of death, a post-mortem examination was performed and then all of the organs inside the abdominal cavities were observed. The stomach was severely expanded and filled with dark-brown colored foreign materials, including ground grass and intact sardines (Fig. 1A). The intestine was pale red in color and its insides were almost empty. The intestine was observed to bear 7 small nodules that measured $5-8 \mathrm{~mm}$ in diameter (Fig. 1B). The nodules had a thick wall and globular shape. They were much lighter than the normal intestinal surface. Each nodule was opened to the intestinal lumen via a perforation in the mucosal surface. The nodules contained flukes, whose posterior parts protruded from the nodule into the intestinal lumen (Fig. 1C). To collect the flukes, a small incision was made on the outer surface of the nodules and the nodules were squeezed until the flukes were expelled. The recovered worms were counted and transferred into $0.9 \%$ saline. In total, 5 adult and 4 young adult flukes were collected from the intestine (Fig. 1D).

Three of the adult worms were subjected to morphological examinations. They were pressed under a cover glass with $10 \%$ formalin, stained with Semichon's acetocarmine, and observed under light microscopy. All other worms were stored in 70\%

Table 1. Morphometric data of Chaunocephalus ferox $(\mu \mathrm{m})$

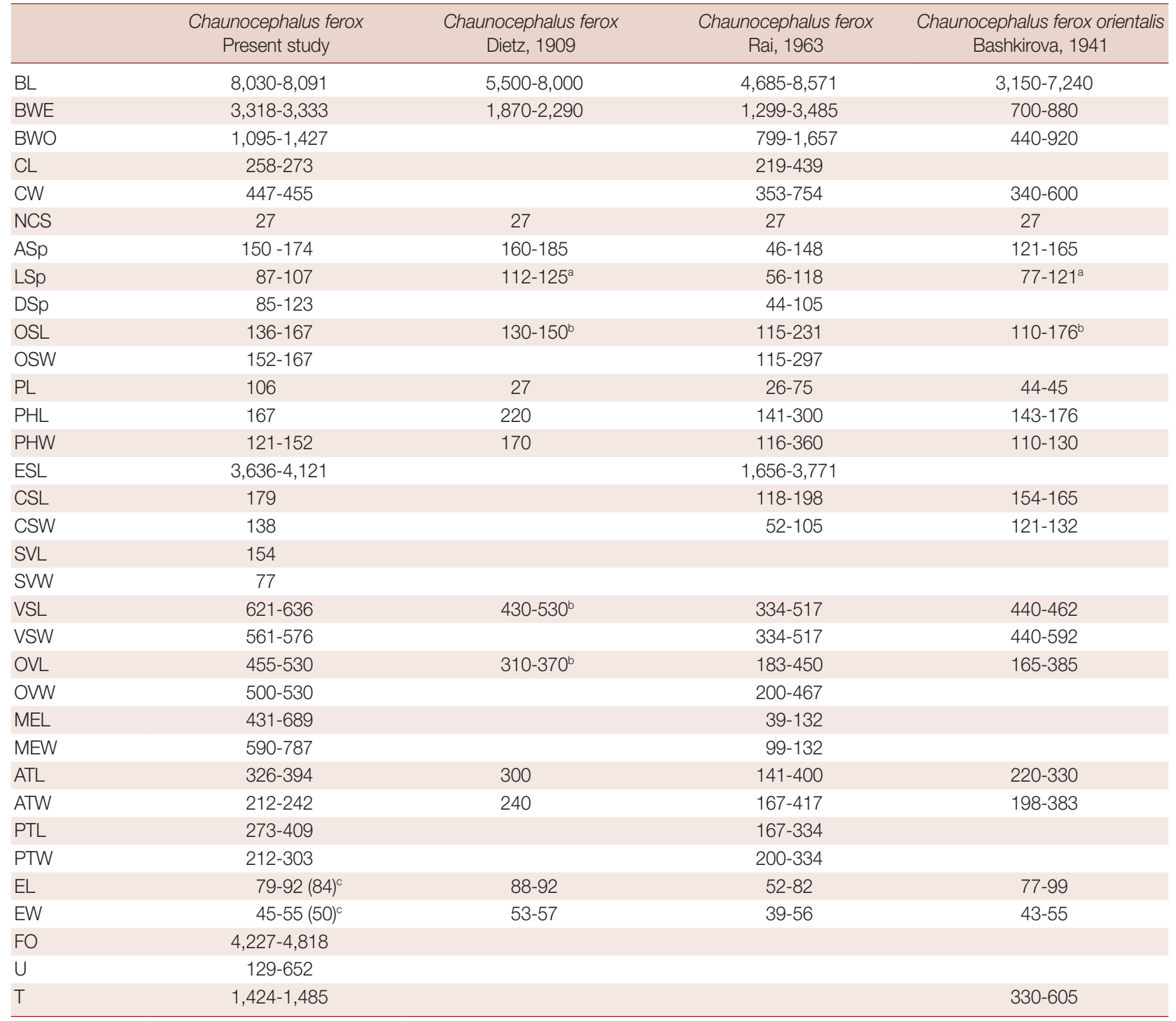

${ }^{a}$ Both of lateral and dorsal spines; ${ }^{b}$ Diameter; ${ }^{\mathrm{N}} \mathrm{N}=30$. 
ethyl alcohol. The mounted worms underwent morphological examinations under a light microscope. The various structures of the worms were measured using a micrometer. The worms then underwent morphometric measurements according to the method described by Kostadinova [13]. Various structures of the worms were observed under a light microscope and measured. Abbreviations used in the present study are as follows: BL: body length; BWE: body width at mid-level of esophagus; BWO: body width at ovary; CL: collar length; CW: collar width; NCS: number of collar spine; ASp: angle spine length; LSp: lateral spine length; DSp: dorsal spine length; OSL: oral sucker length; OSW: oral sucker width; PL: prepharynx length; PHL: pharynx length; PHW: pharynx width; ESL: esophagus length; CSL: cirrus sac length; CSW: cirrus sac width; SVL: seminal vesicle length; SVW: seminal vesicle width; VSL: ventral sucker length; VSW: ventral sucker width; OVL: ovary length; OVW: ovary width; MEL: Mehlis' gland length; MEW: Mehlis' gland width; ATL: anterior testis length; ATW: anterior testis width; PTL: posterior testis length; PTW: posterior testis width; EL: egg length; EW: egg width; FO: forebody length (distance from the anterior end to the anterior margin of the ventral sucker); $\mathrm{U}$ : uterine field length (distance from the anterior margin of the ovary to the posterior margin of the ventral sucker); and T: post-testicular field length. The specimens studied are deposit-
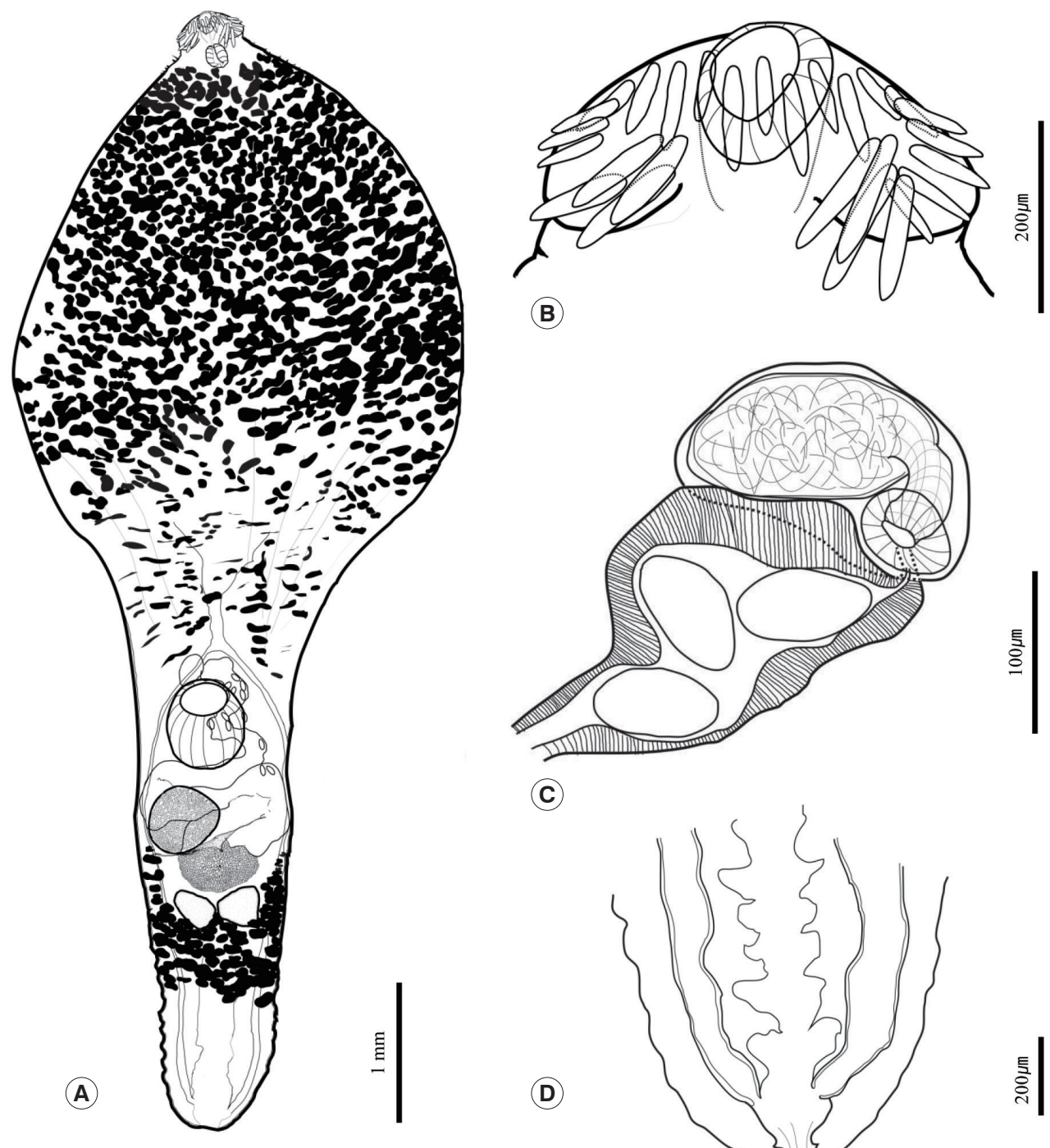

(C)

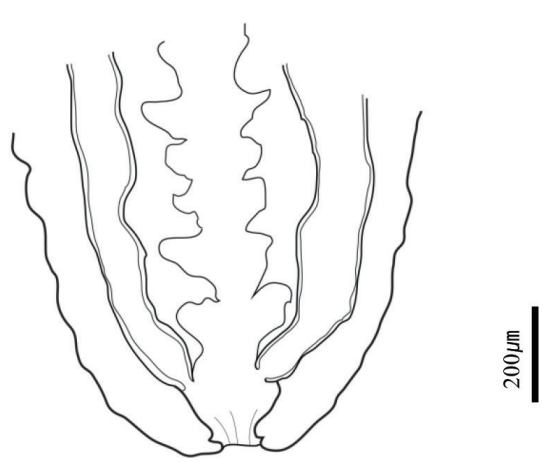

Fig. 2. Morphological features of mature adult Chaunocephalus ferox found in an oriental white stork. (A) Depiction of the whole body. (B) Head region showing a well-developed collar with 27 collar spines around the oral sucker. (C) Terminal genitalia. (D) The chambered excretory vesicle with a uroproct. 
ed in the National Institute of Biological Resources in Korea (NIBR). NIBR specimen numbers are KOSPIV0000221889 and KOSPIV0000221890.

Since 1 of the 3 adult worms was broken, the present case report presents the morphological findings of the remaining 2 adult worms. Morphometric measurements of their features are provided in Table 1. In both worms, the body was anteriorly bulbous, with maximum width at mid-level of esophagus ( $\mathrm{BWE} / \mathrm{BL}=41 \%)$. The posterior body was subcylindrical, with maximum width at ovary level $(\mathrm{BWO} / \mathrm{BL}=14-18 \%)$. The head was small and had a well-developed collar. The collar was reniform and armed with 27 collar spines. The spines were composed of 4 pairs of angle spines, 4 pairs of lateral spines, and 11 dorsal spines. The angle spines were large, the lateral spines were small, and the dorsal spines were aligned in double rows. The oral sucker was spherical and well developed. The prepharynx was short. The pharynx was muscular, short, and stout. The neck region was bulbous and filled with vitelline follicles. The esophageal region was very long and seemed to expand widely $(\mathrm{ESL} / \mathrm{BL}=45-51 \%)$; however, the vitelline follicles made it difficult to observe the esophageal region properly. The intestine was bifurcated at the end of the bulbous region of the neck. The cirrus sac was small, oval shaped, and located between the intestinal bifurcation and ventral sucker. The seminal vesicle lay in the cirrus sac and was connected to the short pars prostatica. The genital pore was located slightly posterior to the intestinal bifurcation. The ventral sucker was spherical and larger than the oral sucker. The ovary was also spherical and bigger than the testes. It was located on the dextral region of and behind the ventral sucker. The uterus was filled with numerous eggs; it ran along the sinistral side of the body and was connected to the genital pore $(\mathrm{U} / \mathrm{BL}=1-8 \%)$. The metraterm was thick, well developed, and muscular. It was longer than cirrus sac. The eggs were yellowish brown and oval shaped. The testes were aligned transversely, were similar in size, were spherical, and reached the posterior margin of the Mehlis' gland. Mehlis' gland was slightly smaller than ovary and was located median region between ovary and testes. The vitelline reservoir was located at the Mehlis' gland region and connected to both sides. Vitelline follicles were situated near the Mehlis' gland and were distributed along both sides to the posterior margin of the pharynx and behind the testes region, although they never reached the end. They were densely distributed in the anterior bulbous region but became fewer towards the posterior end. The vitelline follicles between the ventral sucker and Mehlis' gland region were obscure but appeared as duct-like structures on each side of the body and then densely redistributed behind the testes. The excretory vesicle was well developed and formed several chambers. The intestines connected to the excretory vesicle at the posterior end of the body and formed a uroproct and the opening situated at terminal of posterior end (Fig. 2).

\section{DISCUSSION}

The genus Chaunocephalus is a group of echinostomatid flukes having a bulbous forebody, a short narrow subcylindrical hindbody, and a long esophagus as distinct morphological characteristics. This fluke group is also known to be armed with 25,27 , or 29 collar spines [13]. The recovered worms in the present study were morphologically coincided with the aforementioned characteristics of genus Chaunocephalus with 27 collar spines, which consisted of 4 larger angle spines in each corner and 19 smaller spines on the dorsal and lateral regions.

As the members of the genus Chaunocephalus with 27 collar spines, total 4 species and 1 subspecies, i.e., C. ferox (Rudolphi, 1795) Dietz, 1910; C. gerardi Gedoelst, 1913; C. similiferox Verma, 1936; C. sinensis Ku et al., 1974, and C. ferox orientalis Bashkirova, 1941, were reported in the past $[4,14]$. Mendheim [15] previously suggested that $C$. similiferox is a synonym of $C$. ferox. However, Skrjabin and Bashkirova [4], who developed keys to the species, did not agree; instead, they thought that $C$. similiferox can be distinguished from $C$. ferox on the basis that it has a uroproct and C. ferox does not. However, both Odhner [16] and Travassos [17] reported that $C$. ferox has a uroproct. This notion was supported by Yamaguti [6]. A uroproct was also observed in the worms that were examined in the present study. When Rai [18] assessed the morphology of the parasites collected from Neophron percnopterus and A. oscitans, they concluded that Mendheim was correct and that $C$. similiferox and C. gerardi are synonyms of $C$. ferox. Another author considered C. ferox orientalis to be a synonym of $C$. ferox [5]. Only 1 other species that armed with 27 collar spines, $C$. sinensis, which is found only in China, is thought to be a valid species [14]. Thus, of the 4 postulated species of Chaunocephalus with 27 spines, there appears to be only 2 true species.

Our specimens generally bore the morphological characteristics and measurements of $C$. ferox. While the widths of the body and ventral sucker of our worms were larger than the 
widths described by Dietz [19], this disparity could reflect variations in the amount of pressure placed on the worms when preparing the slide specimens. Indeed, our measurements are similar to those of Rai [18]. On the other hand, whereas the vitelline follicles are arranged transversely and distributed to the posterior extremity in C. sinensis [14], they never reached the posterior end of our specimens. Therefore, we validly concluded that our worms are identical to C. ferox based on the morphological characteristics and taxonomic circumstance.

Poonswad et al. [8] and Patnaik et al. [7] suggest that the pathogenicity of $C$. ferox depends on the number of mature worms and large adults, respectively. In our case, the whole intestine had only 7 nodules, from which we retrieved 9 worms. Moreover, of the 9 worms, 5 were immature or young adult worms. Thus, the infection in our case was relatively minor compared with that in previously reported cases [7-12]. However, we did observe thickening of the intestinal wall that might acted as a risk factor for intestinal obstruction and gastric impaction. Han et al. [20] reported that gizzard impaction is a relatively common problem in captive oriental white storks in Korea. They speculated that the cause of the impaction is unnoticed factors in the breeding cage suggesting that storks cannot digest grass and that its accumulation is the main cause of the impaction [20]. In the present case, the gizzard impaction seems associated with the presence of intestinal nodules containing $C$. ferox flukes.

The fact that we detected immature worms in our case suggests that the infection occurred in the rehabilitation center. The dead stork was 11 years old and had been maintained in KIOWSRR for several years. This means that the life cycle of $C$. ferox flukes in our case was almost certainly completed in Korea. However, at present, the source of infection is still unknown. Yanchev and Bozhkov [21] found 5 mature C. ferox orientalis in white storks that had been fed the spinal cords of Pelophylax ridibundus (= Rana ridibunda) that contained Tylodelphis rhachiaea metacercariae. They speculated that the C. ferox orientalis flukes arose from natural infection of either the frogs or storks [25]. Whereas, Patnaik et al. [7] noted that their $C$. ferox-infected A. oscitans cases in Nandankanan Zoo had been maintained on a snail diet. In other case, Poonswad et al. [8] found snails in the esophagus and stomach of their wild $C$. ferox-infected A. oscitans. All storks raised in KIOWSRR are generally fed loaches, sardines, chicks, and insects (and sometimes also the Asian swamp eel Monopterus albus and Japanese eel Anguilla japonica). They were raised in big outdoor cages with small ponds and living snail hosts.

Although we did not confirm the source of infection in the present study, it could be findable in the cages or provided preys. Further studies on the metacercariae of $C$. ferox will be helpful for preventing chaunocephalosis and improving the health management of storks in rehabilitation centers. In addition, as mentioned by Höfle et al. [9], the storks in the rehabilitation project may need routine examination for $C$. ferox infection using the fecal sedimentation technique.

In conclusion, this report describes the first case of chaunocephalosis from an oriental white stork, C. boyciana in Korea. The fluke C. ferox was identified based on morphological observations. In addition, the present case showed that $C$. ferox could kill its host by inducing gastric impaction, even if the host was infected with only a small number of flukes.

\section{ACKNOWLEDGMENTS}

This work was supported by a grant from the National Institute of Biological Resources (NIBR), which is funded by the Ministry of Environment (MOE) of the Republic of Korea (NIBR no. 2014-02-001). One of the authors (Seongjun Choe) was supported by Graduate Program for the Undiscovered Taxa of Korea (NIBR201524202). The parasite materials used in this study were provided by the Parasite Resource Bank of Korea of the National Research Resource Center (2012-0000037), the Republic of Korea.

\section{CONFLICT OF INTEREST}

We have no conflict of interest related to this work.

\section{REFERENCES}

1. Lee KS, Song MJ. Ciconia boyciana Swinhoe, 1873. In Red Data Book of Endangered Birds in Korea. Seoul, Korea. National Institute of Biological Resources. 2011, pp 77-80 (in Korean).

2. Park SR, Yoon J, Kim SK. Captive propagation, habitat restoration, and reintroduction of oriental white storks (Ciconia boyciana) extirpated in South Korea. Reintroduction 2011; 1: 31-36.

3. BirdLife International. Ciconia boyciana. In The IUCN Red List of Threatened Species. 2013. Version 2015. 1. [www.iucnredlist. org].

4. Skrjabin KI, Bashkirova EY. Family Echinostomatidae Dietz, 1909. In Trematodes of Animals and Man. Essentials of Trematodology. Vol. XII. Moskow, Leningrad, Russia. Academy of Science of the USSR. 1956, pp 51-930 (in Russian). 
5. Chen HT. Fauna Sinica. Platyhelminthes, Trematoda, Digenea (I). Beijing, China. Science Press. 1985, pp 476-480 (in Chinese).

6. Yamaguti S. Systema Helminthum, Vol. I. The Digenetic Trematodes of Vertebrates. New York, USA. Interscience Publishers, Inc. 1958, pp 641-642.

7. Patnaik MM, Rao AT, Acharjyo LN, Mohanty DN. Notes on a nodular disease of the intestine of the open-billed stork (Anastomus oscitans) caused by Chaunocephalus ferox. J Wild Dis 1970; 6: 64-66.

8. Poonswad P, Chatikavanij P, Thamavit W. Chaunocephalosis in a wild population of Asian open-billed storks in Thailand. J Wild Dis 1992; 28: 460-466.

9. Höfle U, Krone O, Blanco JM, Pizarro M. Chaunocephalus ferox in free-living white storks in central Spain. Avian Dis 2003; 47: 506-512.

10. Saad AI. First record on two digenetic trematodes; Chaunocephalus ferox (Rudolphi, 1795) Dietz, 1909 and Cathaemasia hains (Rudolphi, 1809) Looss, 1899 in Egypt and role of the migratory birds in introducing of new parasites to Egyptian fauna. J Egypt Ger Soc Zool 2009: 58; 85-99.

11. Islam S, Talukdar A, Rahman T, Baruah N. Observations on the nodular fluke Chaunocephalus ferox (Rudolphi, 1795) Dietz, 1909 infection in an open billed stork (Anastomus oscitans) from Kaziranga National Park, Assam. J Vet Parasitol 2009: 23; 143-145.

12. Santoro M, Degli Uberti B, Galiero G, Di Prisco F, D’Alessio N,
Veneziano V. Chaunocephalus ferox (Digenea: Echinostomatidae) infection associated with fatal cachexia in a white stork (Ciconia ciconia). Helminthologia 2013: 50; 181-184.

13. Kostadinova A. Family Echinostomatidae Looss, 1899. In Jones A, Bray RA, Gibson DI eds, Keys to the Trematoda. Vol. 2. London, UK. CABI Publishing and the Natural History Museum, 2005, pp 9-64.

14. Ku CT, Chiu CC, Li MM, Chu H. Echinostome fauna from the intestine of the black stork (Ciconia nigra) of China. Acta Zool Sinica 1974; 20: 27-34 (in Chinese).

15. Mendheim H. Beiträge zur systematic und biologie der familie "Echinostomatidae". Arch Natur Leipzig 1943: 12; 175-302.

16. Odhner T. Weitere Trematoden mit anus. Ark Zool Stockh 1928 : 20; $1-6$.

17. Travassos L. Informacoes sobre a fauna helminthological de Matto Grosso. Trematoda II. Mem Inst Oswaldo Cruz 1938: 33; 461-468.

18. Rai SL. Further observations on Chaunocephalus ferox (Rudolphi, 1795) Dietz, 1909. Ind J Helminthol 1963: 15; 6-13.

19. Dietz E. Die Echinostomiden der vögel. Zool Anz 1909: 34; 180192.

20. Han JI, Son HW, Mo IP, Chang DW, Kim S, Park SR, Na KJ. Gizzard impaction with bile stasis in captive oriental white storks (Ciconia boyciana). J Vet Clin 2009; 26: 659-662.

21. Yanchev Y, Bozhkov D. The biology of Proalaria excavata Rud. Dokladi Akademii SSSR 1960: 132; 726-728. 
